\title{
Comparison of the Efficacy and Safety of
}

\section{Dinalbuphine Sebacate, Patient-Controlled Analgesia, and Conventional Analgesia After Laparotomy for Gynecologic Cancers: A Retrospective Study}

\author{
Shu-Han Chang (D) \\ Ting-Chang Chang $\mathbb{D}^{1,2}$ \\ Min-Yu Chen' \\ Wei-Chun Chen ${ }^{1,3}$ \\ Hung-Hsueh Chou',2 \\ 'Department of Obstetrics and \\ Gynecology, Chang Gung Memorial \\ Hospital Linkou Medical Center, Taoyuan, \\ Taiwan; ${ }^{2}$ Chang Gung University, College \\ of Medicine, Taoyuan, Taiwan; \\ ${ }^{3}$ Department of Obstetrics and \\ Gynecology, Chang Gung Memorial \\ Hospital Keelung Branch, Keelung, Taiwan
}

Correspondence: Hung-Hsueh Chou Department of Obstetrics and Gynecology, Chang Gung Memorial Hospital Linkou Medical Center, \#5 Fushing Street, Kwei-Shan, Taoyuan, 333, Taiwan

Tel +886-3328I200

Email ma2012@cgmh.org.tw
Objective: We aimed to investigate the effects of dinalbuphine sebacate (DNS), fentanylbased patient-controlled analgesia (PCA), and conventional analgesia (CA) for pain management after laparotomy for gynecologic cancers.

Methods: A total of 137 eligible patients who underwent laparotomy through a midline incision wound for gynecologic cancer between July 2019 and June 2020 were retrospectively evaluated. The patients were divided into three groups as follows: the intramuscular DNS, intravenous PCA, and CA groups. Postoperative pain (POP) intensity as measured with a numerical rating scale (NRS), total consumption of analgesics, and incidence of treatment-emergent adverse events were compared between the three groups.

Results: The DNS group showed significant reduction in NRS pain intensity than the PCA and CA groups on day 1 (4.8 vs 6.2, p $<0.01$ and 6.2, p $<0.05$, respectively), day 2 (3.0 vs 4.7, $\mathrm{p}<0.01$ and 4.8, p $<0.001$, respectively), day 3 (2.0 vs 3.9, p $<0.001$ and $3.5, \mathrm{p}<$ 0.001 , respectively), day 4 (1.1 vs $3.1, \mathrm{p}<0.001$ and $2.9, \mathrm{p}<0.001$, respectively), and day 5 ( 0.7 vs $2.3, p<0.001$ and $2.4, p<0.001$, respectively). The total consumption of morphine equivalents per day was similar between the DNS and PCA groups $(142.8 \pm 7.3 \mathrm{mg}$ vs 137.7 $\pm 70.0 \mathrm{mg}, \mathrm{p}=0.8032)$ and lowest in the CA group $(11.7 \pm 30.7 \mathrm{mg}, \mathrm{p}<0.0001)$. The overall safety profile was comparable between the DNS, PCA, and CA groups. The patients in the DNS group complained less of dizziness postoperatively than those in the PCA group (27\% vs $47 \%$ ) and had less nausea than those in the CA group (13\% vs $33 \%$ ).

Conclusion: A single DNS injection was more effective for relieving POP than PCA and $\mathrm{CA}$ in the patients who had a longitudinal incision for gynecologic cancer surgery. DNS was well tolerated and had less adverse effects than PCA and CA.

Keywords: dinalbuphine sebacate, postoperative pain, nalbuphine, PCA, laparotomy

\section{Introduction}

Gynecologic cancers, including ovarian, endometrial/uterine, cervical, vulvar, and vaginal cancer, have an increasing trend in the female population aged over 50 years. ${ }^{1}$ More than $80 \%$ of patients who underwent major operations experienced moderate and extreme postoperative pain (POP). ${ }^{2,3}$ Poorly controlled POP causes physiological and psychological consequences and leads to risk of morbidity, complications, delayed wound healing, prolonged hospitalization, and psychological disorder from the traumatic stress. ${ }^{4}$ 
Enhanced recovery after surgery (ERAS) has been developed with the aim of maintaining normal physiology during the perioperative period, leading to improved clinical outcomes. Multiple studies have demonstrated that the implementation of ERAS was associated with reduced length of hospitalization, lower postoperative complication and readmission rates, and accelerated postoperative recovery in various surgical areas, including gynecologic, colorectal, gastrointestinal, orthopedic, vascular, and hepatobiliary area. $^{5-9}$ Appropriate pain management played a significant role in achieving ERAS. Currently, a multimodal opioidsparing regimen involved in multiple drug combinations through different mechanisms of pain control that act synergistically while limiting opioid consumption is the mainstay for perioperative pain management. ${ }^{10}$

Several approaches have proven to show effective control of POP, including conventional analgesia (CA) given as needed, patient-controlled analgesia (PCA), or pre-emptive analgesia such as extended-release dinalbuphine sebacate (DNS). ${ }^{11-13}$ Although CA could decrease the pain intensity in several minutes, the incidence of adverse events (AEs) was usually significant and even intolerable to patients in the early recovery period. ${ }^{14}$ Patients experience POP before getting medication and psychological stress from making frequent calls for medical care. Systemic intravenous (IV) PCA with opioids such morphine or fentanyl plays an important role in POP control; however, its debilitating side effects such as sedation, nausea, dizziness, and pruritus may lead to delayed postoperative rehabilitation. ${ }^{15}$ DNS (Naldebain ${ }^{\circledR}$ ER Injection, Lumosa Therapeutics Co. Ltd., Taiwan) was developed as a long-acting analgesic that maintains the nalbuphine plasma level at the therapeutic range of up to 7 days through intramuscular (IM) administration. It has shown benefits of less postoperative analgesic consumption and sufficient efficacy in POP pain intensity management. ${ }^{12,16,17}$

In this study, we retrospectively analyzed the clinical data of patients with gynecologic cancer who received laparotomy through a midline incision in a single center. The primary objective of this study was to compare the efficacy, safety, and postoperative indicators between CA, PCA, and DNS for critical recommendation in POP management integrated with ERAS in the future.

\section{Methods and Designs}

\section{Setting and Participants}

The clinical data of 147 patients with gynecologic cancers who underwent laparotomy in our hospital between July 1,
2019, and June 1, 2020, were retrospectively collected. The study protocol was reviewed and approved by the institutional review board of Chang Gung Memorial Hospital (IRB202000594B0) and conducted in accordance with the Declaration of Helsinki. Source data were collected from the Hospital Information System in the department of obstetrics and gynecology of Chang Gung Memorial Hospital. We only collected the clinical data of patients retrospectively and did not interfere with treatment; hence, individual consent for this retrospective analysis was waived. The 137 eligible patients aged between 20 and 80 years who underwent laparotomy through a midline incision for gynecologic cancer were evaluated in this study. The patients received general anesthesia, with American Society of Anesthesiologists (ASA) physical status classes 1 to 3 . Ten patients were excluded for any of the following situations: incomplete POP evaluation with a numerical rating scale (NRS), second-look laparotomy, receiving nerve block for pain control, allergy to local anesthetic agents or morphine, beyond the recommended DNS administration time period (12 to 24 hours before surgery), severe comorbidity (cardiopulmonary disease and cerebrovascular accident), or chronic use of morphine.

\section{Analgesic Regimen}

The 137 eligible patients in this study were categorized into three groups according to the method of postoperative analgesia as follows: DNS, intravenous PCA with fentanyl, or CA. Fifty-two patients in the DNS group received a single dose of IM DNS $\left(150 \mathrm{mg} /{ }^{2} \mathrm{~mL}\right)$ using the Z-track technique into the buttock area 12 to 24 hours before surgery. In Z-track injection, the epidermal and hypodermal layers of the subcutaneous tissue were moved 2 to $3 \mathrm{~cm}$ to the side by the nondominant hand while performing the deep muscle injection in the gluteus maximus in the buttocks by the dominant hand. ${ }^{18}$ Fifty-five patients in the PCA group received IV PCA with fentanyl from recovery through 72 hours after surgery. The PCA device was programmed to administer a bolus dose of $16.56 \mu \mathrm{g}$ fentanyl $(3.125 \mu \mathrm{g} / \mathrm{mL}, 5.3 \mathrm{~mL})$ at an infusion rate of $4.2 \mathrm{~mL} / \mathrm{hr}$. The mean lockout interval was $5.3 \mathrm{~min}$. The basal infusion rate was $1.5 \mathrm{~mL} / \mathrm{hr}$ in the PCA group. If PCA with fentanyl was deemed unnecessary by patients, the PCA machine could be removed 48 hours after surgery. In CA regimens, 30 patients received IV parecoxib $40 \mathrm{mg}$ within 3 hours before the surgery, in accordance with the internal 
guideline in Chang Gung Memorial Hospital. Patients with NRS scores of 5 or above from any group may receive rescue analgesic medications, including IM nalbuphine $10 \mathrm{mg}$, IV parecoxib $40 \mathrm{mg}$, IV fentanyl 25/50 $\mathrm{mcg}$, IV morphine $2-10 \mathrm{mg}$, and IV ketorolac $30 \mathrm{mg}$. Fentanyl, morphine, and ketorolac were administered as single-agents in the post-anesthesia care unit at the discretion of anesthesiologist. In the ward, patients received single agent nalbuphine or parecoxib each time when needed according to their personal choice. The quantity and frequency of the rescue medications were recorded in this study.

\section{Pain Assessments}

All the eligible subjects were evaluated for POP using the NRS grading from 0 to 10 , where 0 represents "no pain" and 10 represents "unbearable pain." Serial monitoring of the NRS scores was performed three times a day at 8-hour intervals $(8: 00 \mathrm{am}, 2: 00 \mathrm{pm}$, and 8:00 pm) for six consecutive days (from the operation day to postoperative day 5 or the discharge day). The daily representative NRS score in each patient was analyzed by averaging three NRS scores each day in each patient. The mean NRS score indicated the average of the daily representative NRS score of the patients in the DNS, PCA, or CA groups. Day 0 represents the operation day. Days 1 to 5 represent the first day to the fifth day after operation, respectively.

\section{Endpoints}

The endpoints were comparisons of the differences in NRS pain scores from day 0 through day 5 , total postoperative morphine equivalents per day, time of ambulation, and first time of flatulence between the different groups. Treatmentemergent AEs (TEAEs) were observed and recorded from the time of investigational drug administration through day 5 or discharge day. The severity of each AE was assessed using the National Cancer Institute-Common Terminology Criteria for Adverse Events (NCI-CTCAE)

\section{Data Analysis}

Statistical analysis was performed using the SPSS software package. Results were presented as mean \pm SD. Student's $t$-test was used for numerical variables, and chisquare test or Fisher exact test was used for categorical variables. The consumption of morphine equivalent dose was calculated by applying the conversion ratio of fentanyl to morphine as 0.01 to 1 and nalbuphine to morphine as 1 to $1 .{ }^{19}$ One-way analysis of variance (ANOVA) was performed to compare the difference in the consumption of analgesics among the DNS, PCA, and CA groups. Post hoc analysis using Dunnett's multiple comparisons test was conducted to examine differences by comparing DNS to CA and DNS to PCA. Statistical significance was defined as $\mathrm{p}<0.05$.

\section{Results \\ Patient Clinical Characteristics}

During the study period, a total of 147 patients underwent laparotomies for gynecologic cancers, and 137 patients were included in the study after excluding those who did not meet the inclusion criteria. Fifty-two patients were included in the DNS group; 55 in the PCA group; and 30 in the CA group (Figure 1). Demographics and baseline characteristics were summarized in Table 1. The patients' characteristics, including age, weight, body mass index, incision site, postoperative length of hospital stay, and ASA score, were similar between the groups. The patients were diagnosed as having ovarian, uterine, or cervical cancer. Among the 137 patients, the percentage of patients with ovarian cancer was relatively higher in the DNS group than in the PCA or CA group (Table 1).

\section{Efficacy Outcomes}

POP was measured from day 0 to 5 using the NRS. The DNS group showed significantly lower NRS scores than the PCA and CA groups on day 1 (4.8 vs $6.2, \mathrm{p}<0.01$ and $6.2, \mathrm{p}<0.05$, respectively), day 2 (3.0 vs $4.7, \mathrm{p}<$ 0.01 and $4.8, \mathrm{p}<0.001$, respectively), day 3 (2.0 vs 3.9 , $\mathrm{p}<0.001$ and 3.5, p $<0.001$, respectively), day 4 (1.1 vs $3.1, \mathrm{p}<0.001$ and $2.9, \mathrm{p}<0.001$, respectively), and day 5 ( 0.7 vs $2.3, p<0.001$ and $2.4, p<0.001$, respectively; Figure 2). Meanwhile, the DNS group showed a significantly shorter time to ambulation than the PCA group $(2.5 \pm 1.3$ days vs $3.2 \pm 1.4$ days; $p=0.008)$, similar time to ambulation when compared with the CA group $(2.5 \pm 1.3$ days vs $2.0 \pm 0.9$ days, $\mathrm{p}=0.052)$. In addition, DNS group showed no significant difference in time to flatulence when compared with the PCA group ( $3.0 \pm 1.4$ days vs $3.0 \pm 1.1$ days, $p=0.979)$, but showed longer time when compared with the CA group $(3.0 \pm 1.4$ days vs $2.1 \pm 1.0$ days, $\mathrm{p}=0.005$ ). The total consumption of morphine equivalents per day was similar between the DNS and PCA groups $(142.8 \pm 7.3 \mathrm{mg}$ vs $137.7 \pm$ $70.0 \mathrm{mg}, \mathrm{p}=0.8032)$ and lowest in the CA group (11.7 $\pm 30.7 \mathrm{mg}, \mathrm{p}<0.0001$; Table 2). The parecoxib dose was 


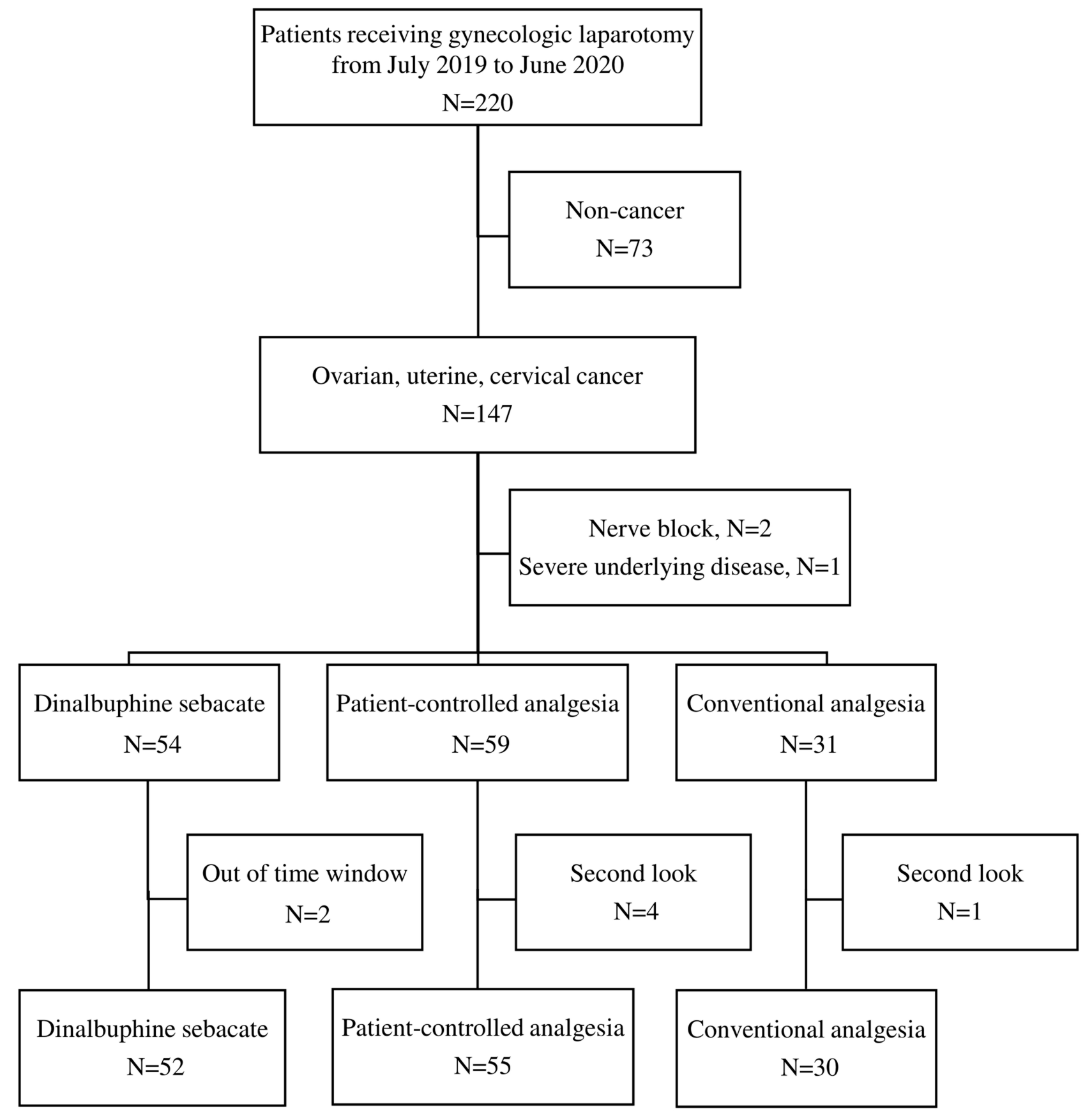

Figure I Flow chart of participants in this study.

significantly higher in the CA group than in the DNS group $(118 \pm 121.6 \mathrm{mg}$ vs $30.8 \pm 64.2 \mathrm{mg}, \mathrm{p}<0.0001)$ but was not significantly different between the DNS and PCA groups $(30.8 \pm 64.2 \mathrm{mg}$ vs $33.5 \pm 36.7 \mathrm{mg}, \mathrm{p}=$ 0.9745). In addition, no significant difference in ketorolac dose was found among the three groups.

No significant difference was found in fentanyl dose between the DNS, PCA, and CA groups either during the induction $(79.8 \pm 29.7 \mathrm{mg}$ vs $72.7 \pm 27.0 \mathrm{mg}$ vs $69.2 \pm$
$24.3 \mathrm{mg}, \mathrm{p}=0.198)$ or maintenance phase $(115.2 \pm 49.3 \mathrm{mg}$ vs $121.1 \pm 53.5 \mathrm{mg}$ vs $120.8 \pm 61.5 \mathrm{mg}, \mathrm{p}=0.830$; Table 3 ).

\section{Safety and Adverse Effects}

The incidence rates of TEAEs are presented in Table 4, and all TEAEs were CTCAE grade $1 / 2$ in severity. In the DNS group, 14 patients (27\%) experienced dizziness; 10 (19\%), nausea; 9 (17\%), vomiting; and $6(12 \%)$, pain at the injection site. Other than pain, no local erythema or 
Table I Patient Characteristics

\begin{tabular}{|c|c|c|c|c|c|c|}
\hline \multirow[b]{2}{*}{ Age (yr.) } & \multicolumn{2}{|c|}{ DNS $n=52$} & \multicolumn{2}{|c|}{ PCA $n=55$} & \multicolumn{2}{|c|}{$C A n=30$} \\
\hline & 52.4 & $( \pm 12.7)$ & 53.5 & $( \pm 12.1)$ & 51.5 & $( \pm 15.9)$ \\
\hline Weight (kg) & 60.8 & $( \pm \mid 1.6)$ & 62.5 & $( \pm \mid 3.1)$ & 61.7 & $( \pm 9.1)$ \\
\hline BMI $\left(\mathrm{kg} / \mathrm{m}^{2}\right)$ & 25.3 & $( \pm 4.8)$ & 25.4 & $( \pm 5.1)$ & 24.9 & $( \pm 3.8)$ \\
\hline \multicolumn{7}{|l|}{ ASA } \\
\hline I & 0 & & 0 & & 0 & \\
\hline II & 27 & $(52 \%)$ & 29 & $(53 \%)$ & 17 & $(57 \%)$ \\
\hline III & 25 & $(48 \%)$ & 26 & $(47 \%)$ & 13 & $(43 \%)$ \\
\hline \multicolumn{7}{|l|}{ Diagnosis } \\
\hline Ovarian cancer & 38 & $(73 \%)$ & 20 & $(40 \%)$ & 16 & $(53 \%)$ \\
\hline Uterine cancer & 12 & $(23 \%)$ & 27 & $(49 \%)$ & 11 & $(37 \%)$ \\
\hline Cervical cancer & 2 & $(4 \%)$ & 6 & $(11 \%)$ & 3 & $(10 \%)$ \\
\hline \multicolumn{7}{|l|}{ Incision site } \\
\hline Midline & 45 & $(87 \%)$ & 49 & $(89 \%)$ & 23 & $(77 \%)$ \\
\hline Low midline & 7 & $(13 \%)$ & 6 & $(11 \%)$ & 7 & $(23 \%)$ \\
\hline Length of surgery (hour) & 6.8 & $( \pm 2.8)$ & 5.9 & $( \pm 2.0)$ & 6.1 & $( \pm 1.7)$ \\
\hline Postoperative length of stay (day) & 10.0 & $( \pm 6.8)$ & 11.0 & $( \pm 5.5)$ & 8.4 & $( \pm 4.3)$ \\
\hline
\end{tabular}

Notes: Data were shown as mean $( \pm \mathrm{SD})$ or $n(\%)$.

Abbreviations: ASA, American Society of Anesthesiologists; BMI, body mass index; DNS, dinalbuphine sebacate; PCA, patient-controlled analgesia with fentanyl; CA, conventional analgesia.

infection over the injection site was observed. In the PCA group, the most common TEAE was dizziness, found in 26 patients $(47 \%)$, followed by nausea in 19 patients $(35 \%)$ and vomiting in 15 patients (27\%). In the CA group, 10 patients $(33 \%)$ complained of nausea and 8 patients $(27 \%)$ complained of vomiting. Overall, the safety profile was comparable between the DNS, PCA, and CA groups. A trend of higher dizziness in the PCA group than in the DNS and CA groups was observed. The incidence rates of nausea, vomiting, and retching were lowest in the DNS group.

\section{Discussion}

This retrospective study demonstrated that preemptive administration of DNS in patients with gynecologic cancer who underwent laparotomy is an effective and safe approach for POP management. To our knowledge, this is the first study to evaluate the efficacy of pain relieving

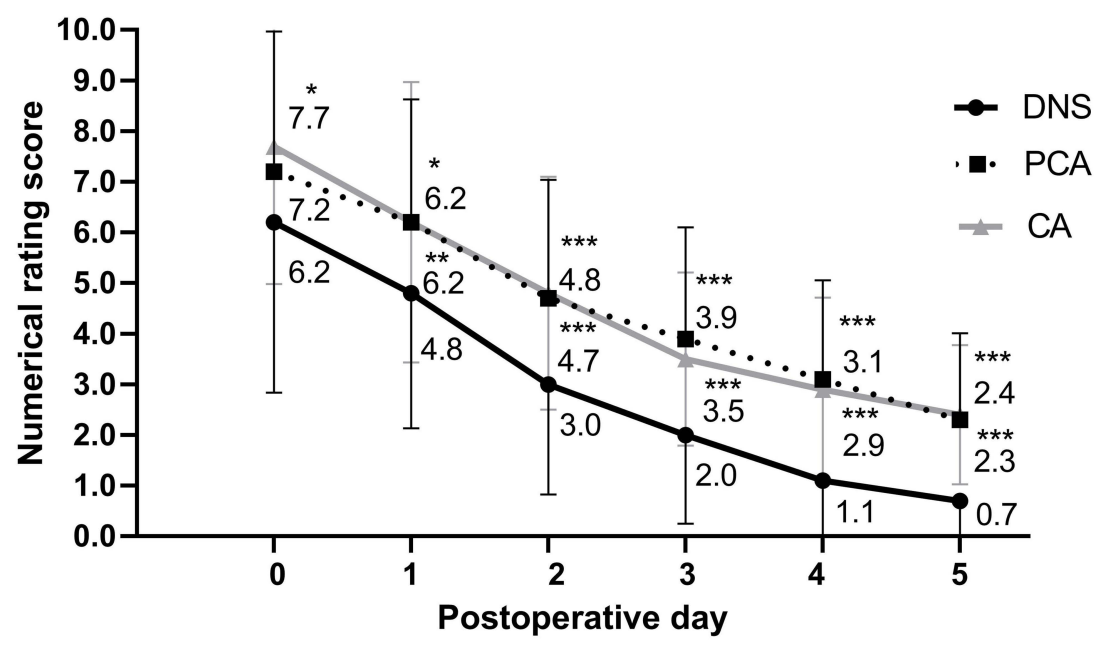

Figure 2 Post-operative pain assessment in patients receiving DNS, PCA or CA from day 0 to day 5 . Notes: ${ }^{*} p<0.05,{ }^{*} p<0.01, * * * p<0.001$. 
Table 2 Consumption of Analgesics

\begin{tabular}{|c|c|c|c|c|c|c|c|c|c|}
\hline \multirow{2}{*}{$\begin{array}{l}\text { Pre-operative Opioid } \\
\text { DNS (mg) }\end{array}$} & \multicolumn{2}{|c|}{ DNS $n=52$} & \multicolumn{2}{|c|}{ PCA $n=55$} & \multicolumn{2}{|c|}{$C A n=30$} & \multirow{2}{*}{$\begin{array}{l}\text { ANOVA } \\
\text { P-value }\end{array}$} & \multirow{2}{*}{$\begin{array}{l}\text { DNS vs } \\
\text { PCA } \\
\text { P-value }\end{array}$} & \multirow{2}{*}{$\begin{array}{l}\text { DNS vs CA } \\
\text { P-value }^{\dagger}\end{array}$} \\
\hline & 136.0 & $( \pm 0.0)$ & N.A. & N.A. & N.A. & N.A. & & & \\
\hline \multicolumn{10}{|l|}{ Post-operative Opioid } \\
\hline PCA-Fentanyl $\left.\right|^{\mathrm{a}}(\mu \mathrm{g})$ & N.A. & N.A. & 1142.9 & $( \pm 852.1)$ & N.A. & N.A. & & & \\
\hline Fentanyl $^{\mathrm{b}}(\mu \mathrm{g})$ & 8.7 & $( \pm 18.5)$ & 3.6 & $( \pm 16.3)$ & 5.8 & $( \pm 15.7)$ & & & \\
\hline Morphine (mg) & 0.3 & $( \pm 1.6)$ & 0.3 & $( \pm I .3)$ & 0.8 & $( \pm 2.1)$ & & & \\
\hline Nalbuphine (mg) & 5.6 & $( \pm 7.0)$ & I.I & $( \pm 4.8)$ & 10.5 & $( \pm 29.4)$ & & & \\
\hline $\begin{array}{l}\text { Postoperative morphine } \\
\text { equivalent dose }(\mathrm{mg})\end{array}$ & 6.8 & $( \pm 7.3)$ & 137.7 & $( \pm 70.0)$ & 11.7 & $( \pm 30.7)$ & $<0.0001$ & $<0.0001$ & 0.8651 \\
\hline $\begin{array}{l}\text { Overall morphine equivalent dose } \\
\text { (mg) DNS included }\end{array}$ & 142.8 & $( \pm 7.3)$ & 137.7 & $( \pm 70.0)$ & 11.7 & $( \pm 30.7)$ & $<0.0001$ & 0.8032 & $<0.0001$ \\
\hline \multicolumn{10}{|l|}{ NSAIDs } \\
\hline Parecoxib (mg) & 30.8 & $( \pm 64.2)$ & 33.5 & $( \pm 36.7)$ & 118.0 & $( \pm|2| .6)$ & $<0.0001$ & 0.9745 & $<0.0001$ \\
\hline Ketorolac (mg) & 1.2 & $( \pm 5.8)$ & 0.0 & $( \pm 0.0)$ & 0.00 & $( \pm 0.00)$ & 0.1669 & 0.1538 & 0.2546 \\
\hline
\end{tabular}

Notes: aPCA-Fentanyl indicated fentanyl administered by PCA device. ${ }^{b}$ Fentanyl indicated fentanyl given intravenously when the patient was admitted to the Post-Anesthesia Care Unit (PACU) after surgery. Data were shown as mean $( \pm S D)$. ${ }^{\dagger} P$ value was performed from $t$-test. $P<0.05$ was considered statistically significant. Abbreviations: DNS, dinalbuphine sebacate; PCA, patient-controlled analgesia; CA, conventional analgesia. N.A., not available.

Table 3 Intraoperative Consumption of Fentanyl

\begin{tabular}{|c|c|c|c|c|c|c|c|}
\hline \multirow{2}{*}{$\begin{array}{l}\text { Induction } \\
\text { Consumption }(\mu \mathrm{g})\end{array}$} & \multicolumn{2}{|c|}{ DNS $\mathrm{N}=52$} & \multicolumn{2}{|c|}{ PCA $N=55$} & \multicolumn{2}{|c|}{ CA $N=30$} & \multirow{2}{*}{$\begin{array}{l}\text { P-value } \\
0.198\end{array}$} \\
\hline & 79.8 & $( \pm 29.7)$ & 72.7 & $( \pm 27.0)$ & 69.2 & $( \pm 24.3)$ & \\
\hline \multicolumn{8}{|l|}{ Maintenance } \\
\hline Consumption $(\mu \mathrm{g})$ & 115.2 & $( \pm 49.3)$ & $|2| . \mid$ & $( \pm 53.5)$ & 120.8 & $( \pm 6 \mid .5)$ & 0.830 \\
\hline Total intraoperative consumption of fentanyl/Length of surgery $(\mu \mathrm{g} / \mathrm{hr})$ & 33 & $( \pm \mid 4.4)$ & 35.3 & $( \pm 15.7)$ & 32.7 & $( \pm \mid 4.4)$ & 0.6403 \\
\hline
\end{tabular}

Notes: Data were shown as mean ( \pm standard deviation). $\mathrm{P}$ value was performed from One-way ANOVA. P $<0.05$ was considered statistically significant. Abbreviations: DNS, dinalbuphine sebacate; PCA, patient-controlled analgesia; CA, conventional analgesia.

Table 4 Summary of Incidence of Treatment Emergent Adverse Events (TEAEs) Reported in Each Study Group

\begin{tabular}{|l|l|l|l|l|l|l|l|}
\hline & \multicolumn{2}{l|}{\begin{tabular}{l}
\multicolumn{2}{l|}{$\begin{array}{l}l \mid \\
\text { DNS } \\
\end{array}$} \\
N=52
\end{tabular}} & \multicolumn{2}{l|}{$\begin{array}{l}\text { PCA } \\
\text { N=55 }\end{array}$} & \multicolumn{2}{l|}{ P-value } \\
\hline Dizziness & 14 & $(27 \%)$ & 26 & $(47 \%)$ & 6 & $(20 \%)$ & $0.017^{*}$ \\
Nausea & 10 & $(19 \%)$ & 19 & $(35 \%)$ & 10 & $(33 \%)$ & 0.172 \\
Vomiting & 9 & $(17 \%)$ & 15 & $(27 \%)$ & 8 & $(27 \%)$ & 0.424 \\
Retching & 0 & $(0 \%)$ & 1 & $(2 \%)$ & 0 & $(0 \%)$ & 0.472 \\
$\begin{array}{l}\text { Injection site } \\
\text { reaction }\end{array}$ & 6 & $(12 \%)$ & 0 & $(0 \%)$ & 0 & $(0 \%)$ & $0.006 *$ \\
\hline
\end{tabular}

Notes: Data were shown as $\mathrm{n}(\%)$. $* \mathrm{P}$ value was performed from Chi square. $\mathrm{P}<0.05$ was considered statistically significant.

Abbreviations: DNS, dinalbuphine sebacate; PCA, patient-controlled analgesia; $\mathrm{CA}$, conventional analgesia.

and safety of DNS in patients with gynecologic cancer who underwent laparotomy and to compare PCA with fentanyl and $\mathrm{CA}$ regimens in real-world practice.
Significantly lower NRS pain scores from day 1 to 5 were observed in the patients who received a single dose of $150-\mathrm{mg}$ IM DNS injection 12 to 24 hours before surgery as compared with those in the PCA or CA group. Consumption of postoperative morphine equivalent was similar between DNS and CA group, but was lower in the DNS group when compared with the PCA group. The overall safety profile was comparable between the DNS, PCA, and CA groups. In addition, DNS showed a significantly shorter time to ambulation than the PCA group.

Gynecologic operations, especially laparotomy with a midline incision for gynecologic cancer, cause severe pain. The commonly used intravenous opioids are IV opioids, morphine and fentanyl, owing to their rapid onset of action with peak effect within 1-2 hours after 
administration. ${ }^{20}$ Fentanyl is a synthetic opioid that is 50 100 times more potent than morphine. ${ }^{21}$ Continuous IV PCA was first introduced in the 1970s. By using a computer-controlled pump, patients are able to obtain additional dose of the drug according to the pain on the spot by themselves. ${ }^{15}$ Being a long-acting nalbuphine, a single-dose, preemptive IM injection of DNS has been reported to result in a significant reduction of posthemorrhoidectomy pain to as long as 7 days after operation. ${ }^{16}$ Furthermore, a randomized controlled study reported that a single dose of DNS was superior to intravenous PCA with fentanyl in patients who underwent laparotomy. ${ }^{12}$ In the present study, the patients received laparotomic staging, debulking, or radical surgery for uterine, ovarian, or cervical cancers. For patients with suspected ovarian cancer, intraoperative frozen section diagnosis was performed during surgery. In addition, some of the selected patients underwent further hyperthermic intraperitoneal chemotherapy (HIPEC) during the surgery. As the above-mentioned procedures required additional operation time, the average operation duration was relatively long (5.9-6.8 hours). Besides, a higher proportion of patients were diagnosed as having ovarian cancer in the DNS group, which resulted in a higher proportion of patients receiving debulking or HIPEC and longer operation time. ${ }^{22}$ These complicated operative procedures might lead to severe POP and longer recovery time in the DNS group. In our study, a trend of lower POP intensity in the DNS group than in the PCA or CA group was observed, which might further support the evidence of the potential analgesic efficacy of DNS for POP management in patients with gynecologic cancer.

Appropriate perioperative patient care plays a critical role in ERAS. ${ }^{23,24}$ Numerous studies reported that multimodal and preemptive analgesia for POP management attained early mobilization, reduced discomfort, and promoted faster recovery. ${ }^{25-27}$ Our study showed that the patients who received preemptive DNS exhibited significantly faster ambulation than those who received PCA group, indicating the beneficial effect of DNS for promoting early recovery in postoperative patient care. Meanwhile, no statistical significance was found in the days to ambulation between the DNS and CA groups. As IV PCA and CA both require a pain management team to conduct POP control, preemptive IM injection of DNS may have a potential to alleviate the burden of the site staff while providing sufficient pain relief.
Owing to its short half-life, nalbuphine requires frequent injection in clinical practice to achieve adequate POP control, resulting in greater incidence of AEs such as sedation, dizziness, nausea, and vomiting. ${ }^{28}$ Tien et al previously demonstrated DNS as an extended-release nalbuphine that takes approximately 6 days to completely release into the bloodstream. ${ }^{29}$ When released, DNS can be rapidly hydrolyzed to nalbuphine by esterase to exert its analgesic effect. Therefore, with a lower maximum blood concentration, DNS has a better safety profile than nalbuphine itself. No opioid antagonism or severe nalbuphineinduced AEs were observed in the DNS group, which may due to the single-dose extended release of DNS resulting in a relatively low maximum plasma concentration of nalbuphine $\left(C_{\max }=16.8 \mathrm{ng} / \mathrm{mL}\right),{ }^{30}$ which led to the lower trend in dizziness, nausea, and vomiting observed in our study. While injection site reactions (ISRs) such erythema and swelling were commonly reported AEs in oil-based IM injection products. ${ }^{31}$ In this study, $12 \%$ of the patients experienced pain, with no local erythema or infection over the injection site. Compared with a previous study that used IM DNS injection for POP control, the present study had a lower incidence of ISR, that is, $27.5 \%$ with erythema or swelling at the injection site versus $12 \%$ with pain. ${ }^{16}$ We believe that this difference was due to the use of the Z-track technique. Applying the Z-track technique for IM injection has shown to reduce drug leakage to the subcutaneous tissue. ${ }^{18}$ Our study also supports the use of the Z-track technique to lower the ISR incidence rate in patients receiving DNS.

As DNS is a kappa opioid receptor agonist and mu opioid receptor antagonist, the strong binding affinity between the mu receptor and DNS may lead to increased fentanyl dose for anesthesia induction. In our study, we found no significant difference in fentanyl dose between the DNS, PCA, and CA groups either during the induction or maintenance phase.

Regional anesthesia such as peripheral nerve blocks, neuraxial anesthesia, and local anesthesia infiltration reported in recent studies showed advantages in safety, such as early ambulation and recovery, shorter length of hospital stay, reduced postoperative nausea and vomiting, and improved pulmonary outcomes. ${ }^{32-34}$ Further study should be conducted to evaluate and compare the efficacy and safety between DNS, regional, and conventional anesthesia and examine the potential of integrating DNS to regional combined with conventional analgesic procedures. 
The study has some limitations that should be mentioned. First, our study was performed in a single center with 30-55 patients in each arm. In addition because the study was retrospective in design, patient demographics was not well balanced and the proportion of patients with ovarian cancer was higher in the DNS group. Second, the pain score was self-rated by the study participants, and the differences in pain threshold and pain tolerance level varied among individuals, which might have caused the discrepancy. The observed effective analgesic ability of DNS may provide evidence of the feasibility of incorporating DNS as part of perioperative pain management in the future.

\section{Conclusion}

Our real-world data showed that a single dose of DNS relieved POP effectively in the patients who underwent a longitudinal abdominal incision for gynecologic cancers and exerted superior pain control as compared with PCA or CA. Further prospective randomized studies are still needed to obtain more information on and firmer evidence of the effects of the drug.

\section{Acknowledgments}

The authors thank all the patients who participate the study. This work was supported by the Chang Gung Memorial Hospital integrated research project, CORPG3J0431.

\section{Disclosure}

The authors report no conflicts of interest in this work.

\section{References}

1. Lin $\mathrm{CH}$, Chen $\mathrm{YC}$, Chiang $\mathrm{CJ}$, et al. The emerging epidemic of estrogen-related cancers in young women in a developing Asian country. Int J Cancer. 2012;130(11):2629-2637. doi:10.1002/ijc.26249

2. Pizzo P. Relieving pain in America: a blueprint for transforming prevention, care, education, and research. Washington (DC). 2011.

3. Ohnesorge H, Gunther V, Grunewald M, Maass N, Alkatout I. Postoperative pain management in obstetrics and gynecology. $J$ Turk Ger Gynecol Assoc. 2020;21(4):287-297. doi:10.4274/jtgga. galenos.2020.2020.0024

4. Gan TJ. Poorly controlled postoperative pain: prevalence, consequences, and prevention. $J$ Pain Res. 2017;10:2287-2298. doi:10.2147/JPR.S144066

5. Nelson G, Dowdy SC, Lasala J, et al. Enhanced recovery after surgery (ERAS(R)) in gynecologic oncology - practical considerations for program development. Gynecol Oncol. 2017;147(3):617-620. doi:10.1016/j.ygyno.2017.09.023

6. Simpson JC, Bao X, Agarwala A. Pain management in enhanced recovery after surgery (ERAS) protocols. Clin Colon Rectal Surg. 2019;32(2):121-128. doi:10.1055/s-0038-1676477
7. Kaye AD, Urman RD, Cornett EM, et al. Enhanced recovery pathways in orthopedic surgery. J Anaesthesiol Clin Pharmacol. 2019;35 (Suppl 1):S35-S39. doi:10.4103/joacp.JOACP_35_18

8. Salenger R, Morton-Bailey V, Grant M, Gregory A, Williams JB, Engelman DT. Cardiac enhanced recovery after surgery: a guide to team building and successful implementation. Semin Thorac Cardiovasc Surg. 2020;32(2):187-196. doi:10.1053/j.semtcvs.2020. 02.029

9. Lillemoe HA, Aloia TA. Enhanced recovery after surgery: hepatobiliary. Surg Clin North Am. 2018;98(6):1251-1264. doi:10.1016/j.suc.2018.07.011

10. Beverly A, Kaye AD, Ljungqvist O, Urman RD. Essential elements of multimodal analgesia in enhanced recovery after surgery (ERAS) guidelines. Anesthesiol Clin. 2017;35(2):e115-e143. doi:10.1016/j. anclin.2017.01.018

11. Costantini R, Affaitati G, Fabrizio A, Giamberardino MA. Controlling pain in the post-operative setting. Int J Clin Pharmacol Ther. 2011;49(2):116-127. doi:10.5414/CP201401

12. Chang TK, Huang CW, Su WC, et al. Extended-release dinalbuphine sebacate versus intravenous patient-controlled analgesia with fentanyl for postoperative moderate-to-severe pain: a randomized controlled trial. Pain Ther. 2020;9(2):671-681. doi:10.1007/s40122-020-00197-x

13. Bollish SJ, Collins CL, Kirking DM, Bartlett RH. Efficacy of patient-controlled versus conventional analgesia for postoperative pain. Clin Pharm. 1985;4(1):48-52.

14. Forst J, Wolff S, Thamm P, Forst R. Pain therapy following joint replacement.A randomized study of patient-controlled analgesia versus conventional pain therapy. Arch Orthop Trauma Surg. 1999;119 (5-6):267-270. doi:10.1007/s004020050407

15. Momeni M, Crucitti M, De Kock M. Patient-controlled analgesia in the management of postoperative pain. Drugs. 2006;66 (18):2321-2337. doi:10.2165/00003495-200666180-00005

16. Yeh CY, Jao SW, Chen JS, et al. Sebacoyl dinalbuphine ester extended-release injection for long-acting analgesia: a multicenter, randomized, double-blind, and placebo-controlled study in hemorrhoidectomy patients. Clin J Pain. 2017;33(5):429-434. doi:10. 1097/AJP.0000000000000417

17. Lee SO, Huang LP, Wong CS. Preoperative administration of extended-release dinalbuphine sebacate compares with morphine for post-laparoscopic cholecystectomy pain management: a randomized study. J Pain Res. 2020;13:2247-2253. doi:10.2147/JPR.S263315

18. Yilmaz D, Khorshid L, Dedeoglu Y. The effect of the Z-track technique on pain and drug leakage in intramuscular injections. Clin Nurse Spec. 2016;30(6):E7-E12. doi:10.1097/NUR.00000000000 00245

19. Mercadante S, Caraceni A. Conversion ratios for opioid switching in the treatment of cancer pain: a systematic review. Palliat Med. 2011;25(5):504-515. doi:10.1177/0269216311406577

20. Lovich-Sapola J, Smith CE, Brandt CP. Postoperative pain control. Surg Clin North Am. 2015;95(2):301-318. doi:10.1016/j.suc.2014. 10.002

21. Dowell D, Haegerich TM, Chou R. CDC guideline for prescribing opioids for chronic pain - United States, 2016. MMWR Recomm Rep. 2016;65(1):1-49. doi:10.15585/mmwr.rr6501e1

22. Wang X, Li T. Postoperative pain pathophysiology and treatment strategies after CRS + HIPEC for peritoneal cancer. World $J$ Surg Oncol. 2020;18(1):62. doi:10.1186/s12957-020-01842-7

23. Paton F, Chambers D, Wilson P, et al. Effectiveness and implementation of enhanced recovery after surgery programmes: a rapid evidence synthesis. BMJ Open. 2014;4(7):e005015. doi:10.1136/ bmjopen-2014-005015

24. Echeverria-Villalobos M, Stoicea N, Todeschini AB, et al. Enhanced recovery after surgery (ERAS): a perspective review of postoperative pain management under ERAS pathways and its role on opioid crisis in the United States. Clin J Pain. 2020;36(3):219-226. doi:10.1097/ AJP. 0000000000000792 
25. Buvanendran A, Kroin JS. Multimodal analgesia for controlling acute postoperative pain. Curr Opin Anaesthesiol. 2009;22(5):588-593. doi:10.1097/ACO.0b013e328330373a

26. Rosero EB, Joshi GP. Preemptive, preventive, multimodal analgesia: what do they really mean? Plast Reconstr Surg. 2014;134(4Suppl 2):85S-93S. doi:10.1097/PRS.0000000000000671

27. Vadivelu N, Mitra S, Schermer E, Kodumudi V, Kaye AD, Urman RD. Preventive analgesia for postoperative pain control: a broader concept. Local Reg Anesth. 2014;7:17-22. doi:10.2147/ LRA.S62160

28. Jaillon P, Gardin ME, Lecocq B, et al. Pharmacokinetics of nalbuphine in infants, young healthy volunteers, and elderly patients. Clin Pharmacol Ther. 1989;46(2):226-233. doi:10.1038/clpt.19 89.130

29. Tien YE, Huang WC, Kuo HY, et al. Pharmacokinetics of dinalbuphine sebacate and nalbuphine in human after intramuscular injection of dinalbuphine sebacate in an extended-release formulation. Biopharm Drug Dispos. 2017;38(8):494-497. doi:10.1002/bdd.2088
30. Huang PW, Liu HT, Hsiong CH, et al. Simultaneous determination of nalbuphine and its prodrug sebacoly dinalbuphine ester in human plasma by ultra-performance liquid chromatography-tandem mass spectrometry and its application to pharmacokinetic study in humans. Biomed Chromatogr. 2013;27(7):831-837. doi:10.1002/bmc.2867

31. Greenblatt DJ, Koch-Weser J. Intramuscular injection of drugs. $N$ Engl J Med. 1976;295(10):542-546. doi:10.1056/NEJM197609022951006

32. Smith LM, Cozowicz C, Uda Y, Memtsoudis SG, Barrington MJ. Neuraxial and combined neuraxial/general anesthesia compared to general anesthesia for major truncal and lower limb surgery: a systematic review and meta-analysis. Anesth Analg. 2017;125 (6):1931-1945. doi:10.1213/ANE.0000000000002069

33. Bajwa SJ, Kulshrestha A. Anaesthesia for laparoscopic surgery: general vs regional anaesthesia. J Minim Access Surg. 2016;12(1):4-9. doi:10.4103/0972-9941.169952

34. Hutton M, Brull R, Macfarlane AJR. Regional anaesthesia and outcomes. BJA Educ. 2018;18(2):52-56. doi:10.1016/j.bjae.2017. 10.002

\section{Publish your work in this journal}

The Journal of Pain Research is an international, peer reviewed, open access, online journal that welcomes laboratory and clinical findings in the fields of pain research and the prevention and management of pain. Original research, reviews, symposium reports, hypothesis formation and commentaries are all considered for publication. The manuscript management system is completely online and includes a very quick and fair peer-review system, which is all easy to use. Visit http:// www.dovepress.com/testimonials.php to read real quotes from published authors. 